\section{Construção de um modelo para análise da assimetria de informação nas transações de laranja*}

\section{Construction of a model for analysis of information asymmetry in orange transactions}

\author{
Barbara Johann Borges ${ }^{1}$ \\ Deisy Cristina Correa Igarashi ${ }^{2}$ \\ Flávia Mayara Segate 3
}

\begin{abstract}
Resumo
O estudo busca compreender a percepção do produtor de laranja sobre a assimetria informacional na comercialização do produto in natura utilizando a metodologia Multicritério em Apoio à Decisão Construtivista (MCDA-C), com base na Economia dos Custos de Transações (ECT). Para tanto, realizou-se entrevistas semiestruturadas com três produtores de laranja do noroeste do Paraná. A MCDA-C foi operacionalizada em três fases: estruturação, avaliação e recomendações. A primeira fase envolve uma pesquisa teórica, a qual identificou uma preocupação com a assimetria de informação; na segunda fase buscou-se na ECT elementos que permitem o entendimento da assimetria da informação. O resultado abrange três pontos de vistas fundamentais: oportunismo, incerteza e frequência. A partir disso, foi possível elaborar os descritores. $\mathrm{Na}$ modelagem permitiu-se a análise do comportamento das transações de laranja. Nenhum dos pontos mapeados apresentou desempenho acima do esperado pelos decisores e apenas o descritor doença apresentou desempenho abaixo do neutro.
\end{abstract}

Palavras chave: Avaliação Multicritério de Apoio à Decisão. Economia dos Custos de Transação. Assimetria da Informação.

\begin{abstract}
The study seeks to understand the orange producer's perception of the informational asymmetry in the commercialization of the product in natura using the Multicriteria Methodology in Support of the Constructivist Decision (MCDA-C) based on Transaction Cost Economics (ECT). For that, were conducted semi-structured interviews with three orange growers from the northwest of Paraná. The MCDA-C was operationalized through three phases: structuring; evaluation; and recommendations. The first phase involves a theoretical research, which identified a concern with information asymmetry; in the second phase, we sought in the ECT elements that allowed the understanding of information asymmetry. The result was three fundamental points of view: opportunism, uncertainty, and frequency. From this, it was possible to elaborate the descriptors. In the modeling, it was possible to analyze the behavior of the orange transactions. None of the mapped points presented performance above that expected by the decision makers and only the "disease" descriptor presented performance below the neutral.
\end{abstract}

Key-words: Multicriteria Decision Support Evaluation; Transaction Cost Economics; Asymmetry of Information.

\footnotetext{
${ }^{1}$ Aluna de Mestrado em Administração na linha de Marketing e Cadeias Produtivas. Universidade Estadual de Maringá (UEM). barbarajohannb@gmail.com

${ }^{2}$ Professora adjunta na Universidade Estadual de Maringá. Doutora em Engenharia de Produção. deisyigarashi@gmail.com ${ }^{3}$ Aluna de Mestrado em Administração na linha de Marketing e Cadeias Produtivas. Universidade Estadual de Maringá (UEM). flaviasegate@gmail.com

*Versão preliminar deste artigo foi apresentada no II Encontro Internacional de Gestão, desenvolvimento e Inovação em novembro de 2018.
}

Artigo recebido em: 01 de abril de 2019. Artigo aceito em 12 de agosto de 2020. 


\section{BORGES; IGARASHI; SEGATE}

\section{Introdução}

O agronegócio tem grande importância na economia brasileira e internacional em diversos setores. Em 2017 o Produto Interno Bruto (PIB) do agronegócio correspondeu a 21,58\% do PIB brasileiro (CEPEA, 2017). A citricultura brasileira tem papel relevante neste cenário, uma vez que o país produz $34 \%$ da laranja mundial e responde por $76 \%$ de no comércio mundial de suco de laranja, conforme o levantamento realizado pelo Departamento da Agricultura dos Estados Unidos (USDA) (CITRUSBR, 2017). Com um parque citrícola que alcança aproximadamente 450 mil hectares, o setor gera um PIB de US\$ 6,5 bilhões de dólares em todos os elos da sua cadeia produtiva (CITRUSBR, 2017).

Apesar de não ser o principal produtor de laranja do Brasil, esta atividade é relevante em termos econômicos para o agronegócio paranaense, isto porque o valor bruto da produção ultrapassa R 260 milhões; existem mais de 600 produtores rurais especializados na produção da fruta, que empregam mais de 3 mil trabalhadores rurais (CONSECITRUS, 2016; SEAB, 2017). O rendimento dos pomares do Paraná também apresenta destaque em nível brasileiro, dado que enquanto a colheita média é de 553 caixas de 40,8 kg por hectare em diversas regiões, no Noroeste do Paraná a média é de 923 caixas, chegando a 2 mil caixas em determinados locais (DERAL, 2017).

No Paraná a plantação de laranja e a fabricação de suco concentrado estão centralizadas nas regiões noroeste e norte do Estado (SABES, 2012). No período de 2001 a 2010, a produção de laranja do estado aumentou em 94,42\% e cresceu em participação na produção brasileira de $1,78 \%$ em 2001 para 3,25\% em 2010. Esse crescimento aumentou a disponibilidade de laranja para abastecer as agroindústrias produtoras de suco concentrado, que destina uma pequena fração para o mercado doméstico e exporta em grandes proporções para o mercado externo (IBGE, 2010; SEAB, 2017; SABES, 2012).

A comercialização de produtos perecíveis, como a laranja, perpassa por diversos desafios, como a incerteza na produção, no que diz respeito à quantidade e à qualidade do produto; e também de atender as preferências dos consumidores (MELLO, 2008). Neste sentindo, na cadeia da laranja há diversos conflitos e episódios que mudaram as formas de transacionar, como: (a) o fim do contrato padrão - que aumentou a complexidade das relações entre os agentes da cadeia, alterando as condições de 


\section{BORGES; IGARASHI; SEGATE}

negociações e fez surgir novas formas contratuais nas transações comerciais; (b) as agroindústrias que forçam a colheita tardia - com o intuito de reduzir o peso e pagar menos pelo produto; (c) as mudanças no método de pagamento - de peso para conteúdo sólido; (d) a manipulação de índices de cálculo do preço (informação assimétrica); (e) o processo de integração vertical - em direção da produção agrícola, em que as agroindústrias passam a possuir pomares próprios. Estes fatores aumentam o poder de barganha das agroindústrias nas transações com os produtores e limitam as formas de coordenação dos agentes (MELLO; PAULILO, 2009; ITO; ZYLBERSZTAJN, 2016).

Carvalho (2015) aponta o aumento da influência de agroindústrias na negociação, após o fim do contrato padrão, gerando custos transacionais advindos de assimetrias informacionais entre agroindústrias e produtores, particularmente nas negociações e do desenho contratual estabelecido. Ito e Zylbersztajn (2016) discutem que problemas contratuais existem decorrentes da racionalidade limitada, dificuldades de medição, assimetrias de informação e presença de oportunismo. Esclarecem também que ocorrem falhas contratuais, que os contratos são incompletos e que isso ocorre devido aos agentes influenciarem na seleção de termos que deixam lacunas estratégicas a fim de obter vantagens sobre os produtores.

Neste sentido, a coordenação das transações é relevante na produção de laranja, já que houve estreitamento das relações entre os produtores e processadores. Outro ponto colocado como desafio para os agentes do setor são as crescentes exigências do consumidor em relação à variedade, qualidade e segurança dos produtos, que são contrapostos com a incerteza climática, os aspectos da sazonalidade e perecibilidade da produção (MELLO, 2008). Desta forma, estudos sobre as transações são importantes, seja com o intuito de reduzir os custos de transação, amenizar riscos, reduzir comportamento oportunista entre as partes, diminuir a assimetria de informação ou escolher com eficiência a estrutura de governança (MELLO, 2008).

O arcabouço teórico que fundamenta o trabalho é o da Nova Economia Institucional (NEI), sobretudo a Economia dos Custos de Transação. Williamson (1985; 1991) analisa a relação entre as estruturas de governança e as variáveis observáveis das transações e do ambiente institucional. De forma geral, a ECT considera que os agentes podem ser autointeressados, possuem racionalidade limitada e podem agir de modo oportunista em determinadas situações. 


\section{BORGES; IGARASHI; SEGATE}

Assume também que a informação é custosa e distribuída de forma assimétrica entre os agentes, o que implica em contratos incompletos. Assim, decorrem os custos de transação, cuja minimização explica os diferentes arranjos contratuais, que têm por finalidade coordenar as transações de forma eficiente (WILLIAMSON, 1985; AZEVEDO, 2000; FARINA et al., 1997; MONDELLI; ZYLBERSZTAJN, 2008).

A partir do exposto, Carvalho (2015) discorre que no complexo citrícola o mecanismo contratual e a integração vertical predominam frente aos demais mecanismos de controle, porém as assimetrias informacionais causam preocupações para o futuro da cadeia produtiva de laranja. Isso porque o produtor é diretamente prejudicado, pois as disputas por informações são assimétricas por parte das agroindústrias e porque há perda no poder de negociação do produtor.

Neste contexto, a integração das atividades e de recursos estratégicos se configura como um exemplo da assimetria informacional que permeia a relação entre produtores e processadores e afeta diretamente o produtor e os preços da caixa de laranja. Neste contexto, a assimetria informacional, associada ao risco moral, eleva as necessidades de contratos formais e de garantia da reputação dos agentes (CARVALHO, 2015).

Desta forma, esta pesquisa estuda o setor citrícola do noroeste do estado do Paraná e se desenvolve sob a ótica da Nova Economia Institucional, com foco na Economia dos Custos de Transação. Enquanto aspecto teórico, o escopo do estudo é a assimetria de informação e o oportunismo. Utilizou-se a Metodologia Multicritério em Apoio à Decisão construtivista (MCDA) a fim de apoiar o processo decisório dos produtores de laranja, resultando em um modelo que pode apoiar tal processo.

A pesquisa tem como intuito responder a seguinte pergunta: qual a percepção do produtor de laranja sobre a assimetria informacional na comercialização do produto in natura? Desta forma, o objetivo do presente estudo é compreender a percepção do produtor de laranja sobre a assimetria informacional na comercialização do produto in natura.

\section{ECONOMIA DOS CUSTOS DE TRANSAÇÃO}

A Economia dos Custos de Transação surgiu dos estudos de Ronald Coase que apresentou no artigo "The nature of the firm" (1937) uma nova perspectiva, a fim de 


\section{BORGES; IGARASHI; SEGATE}

entender as estratégias empresariais ao mostrar que existem outras despesas, além dos custos de produção, que estão associadas ao funcionamento de mercado, nominadas custos de transação. Neste sentido, a ECT é um ramo micro institucional da NEI, o qual sustenta que a transação é a unidade básica de análise das trocas econômicas.

Para Williamson (1993, p. 103), os custos de transação são os "custos ex ante de preparar, negociar e salvaguardar um acordo bem como os custos ex post dos ajustes e adaptações que resultam, quando a execução de um contrato é afetada, por de falhas, erros, omissões e alterações inesperadas”. Segundo Farina (1999), os custos de transação são os relacionados a: (1) elaborar e negociar um contrato; (2) mensurar e fiscalizar os direitos de propriedade; (3) monitorar o desempenho; (4) organizar a atividade e (5) aos custos de adaptação.

Ao comparar a ECT com outras abordagens que estudam organizações econômicas, Williamson (1985, p.18) destaca:

Economia dos custos de transação (1) é mais micro analítica, (2) é mais auto
consciente sobre seus pressupostos comportamentais, (3) introduz e
desenvolve a importância econômica da especificidade de ativos, (4) se
baseia mais na análise comparativa institucional, (5) diz respeito aos
negócios da firma como uma estrutura de governança, em vez da função
produção, (6) coloca mais peso sobre as instituições de contrato ex post, com
ênfase especial na ordem privada (em comparação com a ordem judicial).

$\mathrm{Na}$ economia dos custos de transação Williamson (1985, p. 40) caracteriza a natureza humana da forma como conhecemos a partir de dois pressupostos comportamentais: racionalidade limitada, que "reconhece limites na competência cognitiva"; e o oportunismo, que "pode ser sutilmente substituído pela simples busca do autointeresse". A racionalidade limitada, que, segundo Williamson (1985) representa o pressuposto sobre o qual reside a ECT, é caracterizada por presumir que os agentes econômicos tendem a ser intencionalmente racionais, porém essa capacidade cognitiva é naturalmente limitada e restrita no ato de obter, armazenar, recuperar e processar informações (WILLIAMSON, 1985). Os limites cognitivos resultam em contratos e acordos complexos e incompletos, os quais impossibilitam previsões de riscos futuros, exigindo maior coordenação da cadeia e implicando em contingências futuras e custos de transação maiores (WILLIAMSON, 1985; AZEVEDO, 2000; FARINA, AZEVEDO, SAES, 1997).

O outro pressuposto comportamental definido por Williamson (1985, p. 47) é o comportamento oportunista, que pode ser considerado como uma ação intencional "em que os agentes econômicos buscam seus próprios interesses nas transações, agem em 


\section{BORGES; IGARASHI; SEGATE}

benefício próprio aproveitando-se de lacunas ou omissões contratuais em detrimento dos parceiros". O autor considera este pressuposto uma "busca do autointeresse com avidez", e isto pode incluir flagrantes, roubo, trapaça, entre outros, porém é mais frequentemente associado a formas sutis de fraude.

Para Begnis, Estivalete e Pedroso (2007, p. 313) "na maior parte das vezes, o oportunismo envolve formas sutis de engodo, que tanto podem ser formas ativas ou passivas e também formas ex ante e ex post". As formas expressas como ex ante e ex post são conhecidas respectivamente na literatura econômica como seleção adversa e risco moral (WILLIAMSON, 1985). De maneira geral, na primeira há assimetria informacional que antecede a realização da transação, e na segunda as partes acordam com informação simétrica e posteriormente ocorre a assimetria da informação (RASMUSEN, 1996). Para Williamson (1985), o oportunismo ocorre na maioria dos casos em situações posteriores à transação, pois estas situações não foram previstas contratualmente.

Para este economista, o oportunismo é "responsável por condições reais ou artificiais de assimetria de informação, que complicam significativamente problemas da organização econômica" (WILLIAMSON, 1985, p. 47). A assimetria de informação é responsável por "falhas de mercado" e decorre de quantidades de informações diferentes entre as partes envolvidas, o que reflete na transação e na relação entre elas (WILLIAMSON, 1985; ZYLBERSZTAJN, 2000). Desta forma, há maior espaço para o comportamento oportunista na presença de assimetria de informação, elevando os custos de transação (WILLIAMSON, 1985).

Williamson (1985) destaca que as principais dimensões que diferenciam as transações e podem influenciar nos custos de transação são: frequência, incerteza e especificidade dos ativos. $\mathrm{O}$ atributo frequência é considerado uma medida da recorrência com que uma transação se efetiva (WILLIAMSON, 1985). Para Williamson (1985), Farina (1999) e Azevedo (2000), quanto maior a frequência menores são os custos fixos médios com a coleta de informação e elaboração contratual que imponha restrições ao comportamento oportunista. Nos casos em que a frequência se apresenta como elevada há aumento na confiança entre os agentes e tende a diminuir as perdas nas transações (WILLIAMSON, 1985; AZEVEDO, 2000).

O outro atributo presente nas transações é a incerteza ou risco. Esta característica tem importância especial para o entendimento da ECT, em razão do pressuposto da 


\section{BORGES; IGARASHI; SEGATE}

racionalidade limitada e oportunismo dos agentes, visto que eles são incapazes de estabelecer um contrato que contemple contingências futuras (MELLO; PAULILLO, 2009). Farina (1999) e Azevedo (2000) explicam que a incerteza está presente quando existem lacunas que os contratos e os acordos não conseguem prever. Quanto maior este espaço, maiores são as chances de perdas associadas ao comportamento oportunista entre os agentes (AZEVEDO, 2000).

Quanto à especificidade de ativos, considerada o atributo mais importante e que melhor distingue a ECT das demais teorias econômicas, caracteriza-se por investimentos específicos que não podem ser reempregados sem perder seu valor produtivo, caso um contrato seja interrompido ou a transação não ocorra (WILLIAMSON, 1985). Farina (2000) define ativo específico como todo ativo que pode sofrer perda de valor caso seja usado em outra transação, que não seja aquela que acarretou seu investimento.

Neste sentido, a especificidade de ativos representa o mais importante indutor da forma de governança, o que "corresponde a investimentos duráveis que se realizam em apoio a transações particulares, cujo custo de oportunidade é muito menor nos melhores usos alternativos se a transação original termina prematuramente" (MELLO, PAULILLO, 2009, p. 5).

Para Azevedo (2000, p. 38), "quanto maior a especificidade dos ativos, maior a perda associada a uma ação oportunista por parte de outro agente". Já segundo Balestrin e Arbage (2007), as transações que necessitam de investimentos específicos elevam os custos de transação, visto que sua reutilização não ocorre sem perdas ou de forma imediata. Williamson (1991) aponta seis tipos de especificidades de ativos: (1) locacional; (2) ativos físicos; (3) humanos; (4) dedicados; (5) marca e (6) temporal.

A ECT sustenta que cada organização é definida por formas distintas de direito contratual, que difere entre si em relação a incentivos e controles, o que resulta em modos genéricos de organização, definidos por atributos consistentes que dão origem a forças e fraquezas diferenciadas (WILLIAMSON, 1994). Williamson (1985) sustenta que as estruturas de governança são modos de coordenação que determinam como as transações serão moldadas.

Desta forma, "o conceito de eficiência apoia-se na adequação da estrutura de governança em questão às características da transação à qual ela se vincula" (AZEVEDO, 2000, p. 36). Williamson (1985) ainda explica que estas estruturas seguem 


\section{BORGES; IGARASHI; SEGATE}

um continuum que vão do mercado, passam pelas formas híbridas ou contratuais até a integração vertical ou hierarquia.

As transações ocorrem via mercado quando o nível de especificidade de ativo é baixo ou nulo e os custos de transações, também baixos, assim não há necessidade de controle sobre a transação (WILLIAMSON, 1985; AZEVEDO, 2000). Conforme Williamson (1985), as transações desse tipo são eficientes quando a identidade dos agentes é insignificante, ou seja, existem vários compradores e vários produtores, quando os produtos são padronizados e quando não há forte presença de assimetria de informação.

Para Williamson $(1996,2000)$, quando a especificidade de ativos está presente nas transações é necessária a adoção de uma estrutura de governança especializada, visto que este tipo de transação cria dependência bilateral entre os agentes. Assim, quando a especificidade de uma transação aumenta, os agentes podem optar por uma relação contratual como alternativa ao mercado (WILLIAMSON, 1985). O economista explica que conforme surgem necessidades e custos de renegociação, o nível da especificidade aumenta, os quais o qual, "resulta" em ineficiência pelo mercado e gera a necessidade de migrar para a estrutura híbrida. (WILLIAMSON,1991).

Os agentes buscam estabilidade da relação e comprometimento futuro por meio de contrato, já que são estipulados termos e garantias antecipadamente, o que reduz as chances de comportamento oportunista entre as partes (WILLIAMSON, 1985). Zylbersztajn (2009) afirma que os contratos incorrem em custos de transações e necessitam de salvaguardas como forma de evitar transtornos e comportamento oportunista, além de proteção, caso ocorra quebra contratual.

Williamson (2000) aponta que a questão de incompletude contratual adiciona problemas relacionados ao comportamento oportunista, uma vez que os agentes não cumprirão os termos estipulados no contrato de forma confiável. O contrato conterá apenas promessas que não são sustentadas por compromissos creditáveis, ou seja, os contratos não serão self-enforcing (WILLIAMSON, 2000). Desta forma, quando a especificidade de ativos for alta os custos relacionados a quebra contratual serão altos; nesta situação é relevante maior controle sobre as transações, consequentemente faz-se necessário optar pela integração vertical (AZEVEDO, 2000).

$\mathrm{Na}$ integração vertical ocorre a integração de processos produtivos pela firma, isso decorre quando os custos de internalizar são menores do que os demais 
mecanismos de comercialização, o que implica em maior variedade de incentivos e controles (WILLIAMSON, 1985; AZEVEDO, 2000). Para Williamson (1985, 2000), o principal motivo pelo qual uma firma integraliza suas transações está relacionado à especificidade dos ativos, ou seja, quanto maior a especificidade de ativos, maior é o grau de dependência bilateral entre os agentes, o que torna a integração mais favorável.

Desta forma, não existe uma estrutura de governança que seja superior a outra, mas um alinhamento das transações que tornará a estrutura eficiente ou não às transações às quais estão vinculadas (AZEVEDO, 2000). Em suma, quanto maior a frequência das transações, menores são os custos relacionados a renegociação, coleta de informações e elaboração de contratos, ou seja, como os agentes desenvolvem reputação, limita o interesse em agir oportunisticamente. A incerteza está relacionada a mudanças em prever conflitos futuros, assim, quanto maior a incerteza mais complexas se tornam as relações de longo prazo. Por fim, a especificidade de ativos será mais ou menos importante de acordo com as adaptações necessárias por cada transação, o que resulta em estruturas de governanças distintas.

\section{METODOLOGIA}

Quanto ao delineamento do estudo, caracteriza-se como qualitativo do tipo descritivo. Uma característica importante deste tipo de pesquisa é "oferecer descrições ricas e bem fundamentadas, além de explicações sobre processos em contextos locais identificáveis" (VIEIRA, 2006, p. 18).

A pesquisa qualitativa, por apresentar várias práticas de interpretação, possui multiplicidade de métodos e, portanto, não possui uma teoria ou um paradigma exclusivo (DENZIN; LINCOLN, 2006; VIEIRA; RIVERA, 2012; COLBARI, 2014). Também se caracteriza como um estudo do tipo descritivo - Triviños (1987) aponta que uma pesquisa descritiva tem por objetivo descrever fatos e fenômenos de determinada realidade, a fim de obter informações a respeito de um problema a ser investigado.

Segundo Yin (2005), o método de estudo de caso trata de um fenômeno contemporâneo em um contexto da vida real e seu foco são situações em que os limites entre o fenômeno e o contexto não são claros, o qual utiliza diferentes fontes de informações. O estudo de caso tem como finalidade solucionar "questões do tipo "como" e "por que", quando o pesquisador tem pouco controle sobre os eventos e 


\section{BORGES; IGARASHI; SEGATE}

quando o foco se encontra em fenômenos contemporâneos inseridos em algum contexto da vida real" (YIN, 2005, p. 19).

Desta forma, contribui para a compreensão de fenômenos individuais, organizacionais, sociais e políticos (YIN, 2005). Para Yin (2005), uma variação do estudo de caso é o estudo de caso múltiplo, o qual é utilizado para entender diferentes aspectos de um determinado fenômeno. Lazzarini (1997) afirma que uma vantagem em utilizar este método está atrelada à utilização de mais de uma unidade de análise e na questão de interpretação dos fatos. Neste trabalho, utiliza-se o método de estudo de casos múltiplos, uma vez que são identificados produtores de laranja do noroeste do Paraná que transacionam com diferentes agentes da cadeia.

Adota-se nesta pesquisa a metodologia Multicritério de Apoio à Decisão, segundo a vertente construtivista (ROY, 1993). Para Roy (1993) considera-se o apoio à decisão como uma atividade em que um facilitador obtém elementos de respostas a questões realizadas por atores envolvidos em um processo decisório. Estes elementos esclarecem decisões com finalidade de fornecer possíveis condições para um determinado comportamento, que poderá aumentar a evolução de um processo e as metas em que os atores operam (ROY, 1993).

A MCDA-C é operacionalizada a partir de três fases: a fase de estruturação; fase de avaliação e a fase de recomendações (ENSSLIN; DUTRA, 2000). Neste estudo a primeira fase foi realizada por meio de uma pesquisa teórica, a qual identificou uma preocupação com a assimetria de informação na produção de laranja (MELLO, 2008; MELLO, PAULILO, 2009; CARVALHO, 2015, ITO, ZYLBERSZTAJN, 2016;). Na segunda fase buscou-se na ECT elementos que permitissem o entendimento da assimetria da informação na laranja (WILLIAMSON, 1985). Resultou-se em três pontos de vistas fundamentais, são eles: oportunismo, incerteza e frequência. A partir disso, foi possível elaborar os descritores, conforme descrito na próxima seção.

O contato com os participantes da pesquisa ocorreu diretamente na propriedade do produtor rural de laranja. Obteve-se os dados primários por meio de entrevistas semiestruturadas e observações. Triviños (1987, p. 146) apresenta que a entrevista semiestruturada é "aquela que parte de certos questionamentos básicos, apoiados na teoria [...], e que, em seguida, oferecem amplo campo de interrogativas [...], que vão surgindo à medida que recebem respostas do informante". 


\section{BORGES; IGARASHI; SEGATE}

Já em relação à observação direta, esta foi realizada in loco como forma de se aproximar do objeto de estudo (TURETA e ALCAPANI, 2011). Desta forma, elaborouse um roteiro de entrevista destinado ao produtor rural de laranja. As questões foram construídas a partir dos elementos da ECT e das características da atividade. Na análise de dados são descritos os resultados de três entrevistas realizadas com produtores situados no noroeste do Paraná.

\subsection{PROCEDIMENTOS PARA CONSTRUÇÃO DO MODELO}

A teoria utilizada como base para a construção do modelo foi a ECT, as áreas de interesse são os atributos das transações (incerteza e frequência) e os pressupostos comportamentais (oportunismo). Para descrever a estruturação do modelo, o presente estudo foi subdividido em três etapas: definição de um problema, representação dos pontos de vistas fundamentais (PVF) e construção dos descritores. Seguindo esta lógica, o problema para construção do modelo consistiu em descobrir a percepção do produtor de laranja sobre a assimetria informacional na comercialização do produto in natura.

Na segunda etapa, foram definidos os aspectos fundamentais para a avaliação do problema segundo a percepção dos decisores, ou seja, elaborou-se a família de pontos de vistas fundamentais, os quais determinam os valores que os produtores rurais de laranja (decisores) demonstram como importante para comercializar o produto in natura, constituindo o eixo do problema de pesquisa. Nesta etapa utilizou-se a lógica de decomposição, em que um ponto de vista fundamental é decomposto até ser passível de mensuração (IGARASHI et. al., 2008). Desta forma foram realizadas entrevistas semiestruturas com três produtores de laranja do noroeste do Paraná, os quais transacionam com agroindústrias da região por meio de contratos e acordos verbais, para identificar a percepção dos mesmos em relação aos pontos de vistas fundamentais descritos no modelo.

Por fim, na última etapa, a partir do processo de avaliação dos PVF fez-se necessário a construção de descritores a fim de mensurá-los. Após definir os descritores, foram determinados os níveis de impacto de referência, o nível Bom e o nível Neutro; a partir disso, ficou mais claro identificar as ações satisfatórias e não-satisfatórias (ENSSLIN, MONTIBELLER NETO, NORONHA, 2001). 
Quadro 1: Descritor de avaliação referente ao PV elementar 1.3.2-Violação de acordos

\begin{tabular}{|c|c|c|}
\hline NÍVEL & PERFORMANCE & DESCRIÇÃO \\
\hline 1 & BOM & O processador cumpre mais de $90 \%$ do acordo. \\
\hline 2 & & O processador cumpre de $60 \%$ a $90 \%$. \\
\hline 3 & & O processador cumpre de $30 \%$ a menos $60 \%$ do \\
acordo.
\end{tabular}

Fonte: Dados da pesquisa.

Os níveis de impactos foram ordenados do melhor para o pior. O nível bom demarca as ações acima das expectativas dos decisores, porém podem ocorrer, estas ações representam um desempenho maior do que a expectativa do decisores. Já os níveis que se situam entre o bom e o neutro são os desempenhos esperados pelos decisores. Em relação ao nível de impacto inferior ao neutro, representam desempenhos não-satisfatórios, mas aceitáveis pelos decisores (ENSSLIN, MONTIBELLER NETO, NORONHA, 2001).

\section{ANÁLISE DO MODELO}

Com a finalidade de levantar as características dos produtores buscou-se informações como: tamanho da propriedade, principais produtos produzidos na propriedade, o número de trabalhadores, a produção de laranja por safra, variedade de laranja produzida e o tempo de atividade, conforme apresentado no quadro 2.

Quadro 2: Dados gerais dos produtores entrevistados.

\begin{tabular}{|l|c|c|c|}
\hline \multicolumn{1}{|c|}{ Características } & Produtor A & Produtor B & Produtor C \\
\hline $\begin{array}{l}\text { Área total da propriedade } \\
\text { (ha) }\end{array}$ & 363 & 116,16 & 65,34 \\
\hline Área destinada à laranja (ha) & 260 & 91 & 48,40 \\
\hline
\end{tabular}

Revista Eletrônica Gestão e Serviços v.11, n. 1, pp. 3076 - 3097, Janeiro/Junho 2020. ISSN Online: 2177-7284 e-mail: regs@metodista.br 


\begin{tabular}{|l|c|c|c|}
\hline № de trabalhadores (família) & 2 & 2 & 1 \\
\hline $\begin{array}{l}\text { № de trabalhadores } \\
\text { (funcionários) }\end{array}$ & 8 & 1 & 1 \\
\hline $\begin{array}{l}\text { Tempo na atividade rural } \\
\text { (anos) }\end{array}$ & 40 & 45 & 30 \\
\hline Tempo na atividade (anos) & 16 & 25 & 20 \\
\hline Safra 2016/2017 (caixas) & $280 / 420$ & $30 / 37$ & $32 / 50$ \\
\hline $\begin{array}{l}\text { Variedade de laranja } \\
\text { produzida }\end{array}$ & $\begin{array}{c}\text { Pêra, Pêra Cravo, } \\
\text { Folha Murcha, } \\
\text { Valência, Citro Melo } \\
\text { e Rubi }\end{array}$ & $\begin{array}{c}\text { lapolha Murcha e } \\
\text { Volência e } \\
\text { Pêra }\end{array}$ & $\begin{array}{c}\text { Folha murcha, } \\
\end{array}$ \\
\hline
\end{tabular}

Fonte: Dados da pesquisa.

A pesquisa demonstra que os produtores são proprietários da terra, a maioria oriunda de herança familiar, e estão na atividade há pelo menos 15 anos. Em relação ao uso da terra para atividade da laranja, identificou-se que todos utilizam pelo menos $70 \%$ da área total da propriedade para a produção de laranja. Embora a maioria disponha de outras rendas na propriedade, constatou-se em todos os casos a laranja como atividade principal. Algumas das atividades desenvolvidas para complementar a renda no período entressafra da laranja são: plantação de mandioca, aviário e leite.

Os entrevistados estão, em média, há pelo menos 35 anos na atividade rural, entre os quais pelos menos 20 anos somente na produção de laranja. Em todos os casos a produção é decorrente da atividade familiar, em que os filhos assumem as propriedades dos pais ou tios para dar continuidade à produção. As propriedades são situadas na região noroeste do Paraná, entre os municípios de Paranavaí e Alto Paraná, onde estão localizadas a principais agroindústrias de laranja do estado, conforme dados governamentais.

Em média, duas famílias dependem da propriedade (casal e filhos), em todos os casos o homem (pai da família) responde pelo trabalho físico e gestão da propriedade e geralmente divide o trabalho com um irmão ou outro familiar. Em relação aos trabalhadores assalariados dependentes da produção da propriedade, observou-se em média apenas um funcionário nas propriedades, e em período de safra contrata-se 


\section{BORGES; IGARASHI; SEGATE}

funcionários por diária, com exceção do produtor A, que possui seis ajudantes durante o ano e contrata pelo menos mais trinta no período de safra.

Em relação à produção, foi apurado que em 2017 o volume produzido foi relativamente maior que o do ano anterior, pois todos os produtores apresentaram crescimento no volume de produção. Em geral, no Paraná a produção cresceu em média $50 \%$, o que configurou o fenômeno denominado 'super safra' (DERAL, 2017). Com relação às variedades de laranja plantadas na propriedade, a principais são: a Pêra, Folha Murcha e Valência; visto que são os tipos mais demandados nas agroindústrias, uma vez que o rendimento e o sabor (adocicado e menos ácido) destas variedades são mais apropriados para suco.

A medição da produção é de responsabilidade da agroindústria com a qual o produtor mantém transações via contrato, estipulado pelos mesmos, no que se relaciona aos cuidados básicos com a produção, a lista dos fertilizantes e defensivos agrícolas permitidos na produção. As laranjas entregues à indústria não necessitam ter visual atrativo, porém o rendimento, tamanho e brix (teor de açúcar) são os principais elementos considerados para o processamento do suco.

Como mencionado na seção anterior, com base nos preceitos das ECT, o modelo focou nos atributos de transação e no pressuposto comportamental, que possibilitou a elaboração de três pontos de vistas fundamentais, são eles: oportunismo, incerteza e frequência. Como esses não geraram indicadores passíveis de mensuração, houve necessidade de novas decomposições.

Desse modo, no que concerne ao ponto de vista fundamental "oportunismo", esse foi decomposto em duas subáreas, sendo elas: 2.1 .1 transações ex ante; e 2.1.2 transações ex post. Estas subáreas foram decompostas em outras, uma vez que não poderiam ser mensuradas. Em relação a '2.1.1 transações ex ante' verificou-se que é necessário haver negociação entre os agentes para que ocorra a transação, assim, esta subárea foi dividida em: 2.1.1.1.1 Números de negociação antes da transação; e 2.1.1.1.2 Tempo para ocorrer o acordo. Quanto à subárea 2.1.2 'transações ex post', constatou-se que podem ocorrer '2.1.2.1 Renegociação' e '2.1.2.2 Conflitos na transação', ambos decompostos em outras subáreas para que fosse possível a mensuração. O primeiro foi subdividido em 2.1.2.1.1 Prazo; e 2.1.2.1.2 Preço; já o segundo em 2.1.2.2.1 Honestidade na transação; 2.1.2.2.1.1 Inadimplência e 2.1.2.2.1.2 Violação de acordos. 
O ponto de vista fundamental "incerteza" foi decomposto em quatro subáreas, sendo elas 3.1.1 Negociação; 3.1.2 Confiança; 3.1.3 Produção; e 3.1.4 Preço. O item 3.1.1, pode ser mensurados a partir da decomposição em 3.1.1.1 Período de pagamento; no que concerne ao item 3.1.2, realizou-se a decomposição em subáreas tais como: 3.1.2.1 Medição, de modo geral é realizada por profissionais designados pelas agroindústrias; e 3.1.2.2 Recebimento. Em relação ao item 3.1.3, dividiu-se em duas novas subáreas: 3.1.3.1 Características físicas e 3.1.3.2 Doenças; o primeiro foi subdividido em 3.1.3.1.1 Mercado e 3.1.3.1.2 Agroindústria. E por fim, o 3.1.4, fragmentou-se em 3.1.4.1 Possibilidade de trocar de comprador quando há alteração no preço e 3.1.4.2 Preço de venda. O último ponto de vista fundamental é o atributo 'frequência', que para melhor compreensão foi decomposto em 3.2.1 Fidelização da transação.

Após a estruturação do modelo os descritores de cada ponto de vista fundamental foram detalhados, com a finalidade de compreender a percepção dos produtores rurais sobre as transações. A figura 1, ilustra os pontos de vista elementares, destacando os níveis de impacto bom e neutro, respectivamente 100 e 0 , e como explicado anteriormente, permitem identificar as ações satisfatórias, não-satisfatórias e as variações (ENSSLIN, NETO; NORONHA, 2001).

Conforme Williamson (1985) e Begnis, Estivalete e Pedroso (2007), o oportunismo pode ser reconhecido em formas ex ante e ex post a transação. Neste modelo analisa-se as duas formas. Em relação à forma ex ante, os produtores consideram os números de negociações e o tempo para ocorrer o acordo aceitáveis, uma vez que os contratos são elaborados por uma comissão de produtores em conjunto com as agroindústrias em cada safra e as entregas, efetuadas conforme a necessidade da agroindústria e a disponibilidade frutos - medição estipulada pela própria agroindústria.

Na forma ex post a transação, o prazo de renegociação é anual, assim como a renegociação do preço, com exceção do produtor C. Esse fixou o contrato por dez anos com a mesma agroindústria, a fim de evitar transtornos como incertezas ambientais, falta de comprador para o produto e altos custos de transação, porém o preço continua sendo negociado anualmente conforme o estipulado para as safras.

Os produtores apontam que não ocorre inadimplência nas transações vinculadas à agroindústrias, porém, os três entrevistados afirmaram que deixaram de trabalhar diretamente com o mercado devido aos altos riscos de inadimplência que envolviam as 


\section{BORGES; IGARASHI; SEGATE}

transações. Em relação à violação dos acordos estabelecidos, os produtores discorrem que quase não houve este tipo de comportamento nas transações, de forma geral os processadores cumprem o esperado pelos produtores.

A partir das entrevistas foi possível identificar a presença do atributo frequência, isto porque os produtores de laranja mantêm contratos formais com o mesmo processador ou intermediário há pelos menos 5 anos consecutivos, já que é interesse do próprio produtor ter uma recorrência na transação do seu produto. Um dos motivos pelos quais os produtores passaram a não transacionar diretamente com o mercado é a insegurança relacionada à perda na produção, devido a não haver um comprador disponível sempre e os altos custos de transação que poderiam incorrer nesta transação, uma vez que as transações com o mercado findava em inadimplência e a frequência de entrega do produto não era constante. Este achado corrobora com Carvalho (2015) que demonstra que as transações com o mercado ocasionam assimetria informacional associada ao risco moral, redução de confiança e necessidade de elaboração de contratos formais.

Segundo Williamson (1985), a incerteza decorre de perturbações que podem afetar o processo de troca entre os agentes, o que pode derivar de atitudes aleatórias, mudanças imprevisíveis, falta de informações e de comunicação, bem como problemas decorrentes do comportamento entre os agentes. As principais incertezas decorrentes da comercialização de laranja são: negociação, confiança, produção e preço.

Em relação ao período de pagamento, 20\% deste são realizados 10 dias após a entrega do produto e os demais, após 30 dias. Segundo os produtores, o ideal seria receber à vista, mas o fato de não ocorrer inadimplência torna esta forma de trabalhar eficiente. No que tange à confiança na medição e recebimento, a maioria dos produtores confia que não haverá problemas nestes quesitos, já que a processadora sempre cumpriu com os prazos e preços acordados; além do fato de que quando o volume ultrapassa o que foi medido, a processadora recebe o excedido.

Identificou-se a partir das entrevistas que as características físicas do fruto se diferem quando a transação é realizada para mercado e para agroindústria - enquanto para o primeiro o aspecto da casca (cor), o tamanho e rendimento são levados em consideração, isto porque no mercado os consumidores finais mensuram o produto primeiramente pelo aspecto visual do fruto; para o segundo o rendimento e o tamanho 


\section{BORGES; IGARASHI; SEGATE}

são características mais importantes, uma vez que para o processamento do suco, o aspecto visual não é o fator principal para determinar a qualidade.

Segundos os entrevistados, o fruto pode até estar escurecido, mas o que define a qualidade é o rendimento e o teor de açúcar. Este achado corrobora com os resultados expostos por Mello (2008), em que a qualidade da fruta é de difícil mensuração e desta forma tal incerteza afeta a capacidade de negociar em canais alternativos. Mello (2008) discorre ainda que a qualidade da laranja é um diferencial para negociar preços melhores, assim, a reputação e a confiança no produtor facilitam a transmissão de informações entre os agentes, reduzindo o comportamento oportunista.

Em relação à incerteza de produção, as doenças impactam diretamente no volume de produção, já que é quase impossível garantir que uma doença será controlada, mesmo seguindo as normas técnicas exigidas pelo governo e agroindústria. Neste sentido, a doença que mais preocupa os produtores entrevistados de forma geral, é o Greenig (bacteriana). Segundo a Fundecitrus (2018) essa é a doença mais destrutiva dos citros no Brasil e no mundo, pois após a contaminação do pomar as arvores não produzem e as que ainda produzem sofrem altas quedas dos frutos. Os pomares com incidência da doença devem ser erradicados. No que diz respeito à incerteza derivada do preço, a possibilidade de troca de comprador, quando há alteração no preço, é praticamente nula. Os produtores apontam que a confiança envolvida na transação é o fator fundamental para manter as relações. 


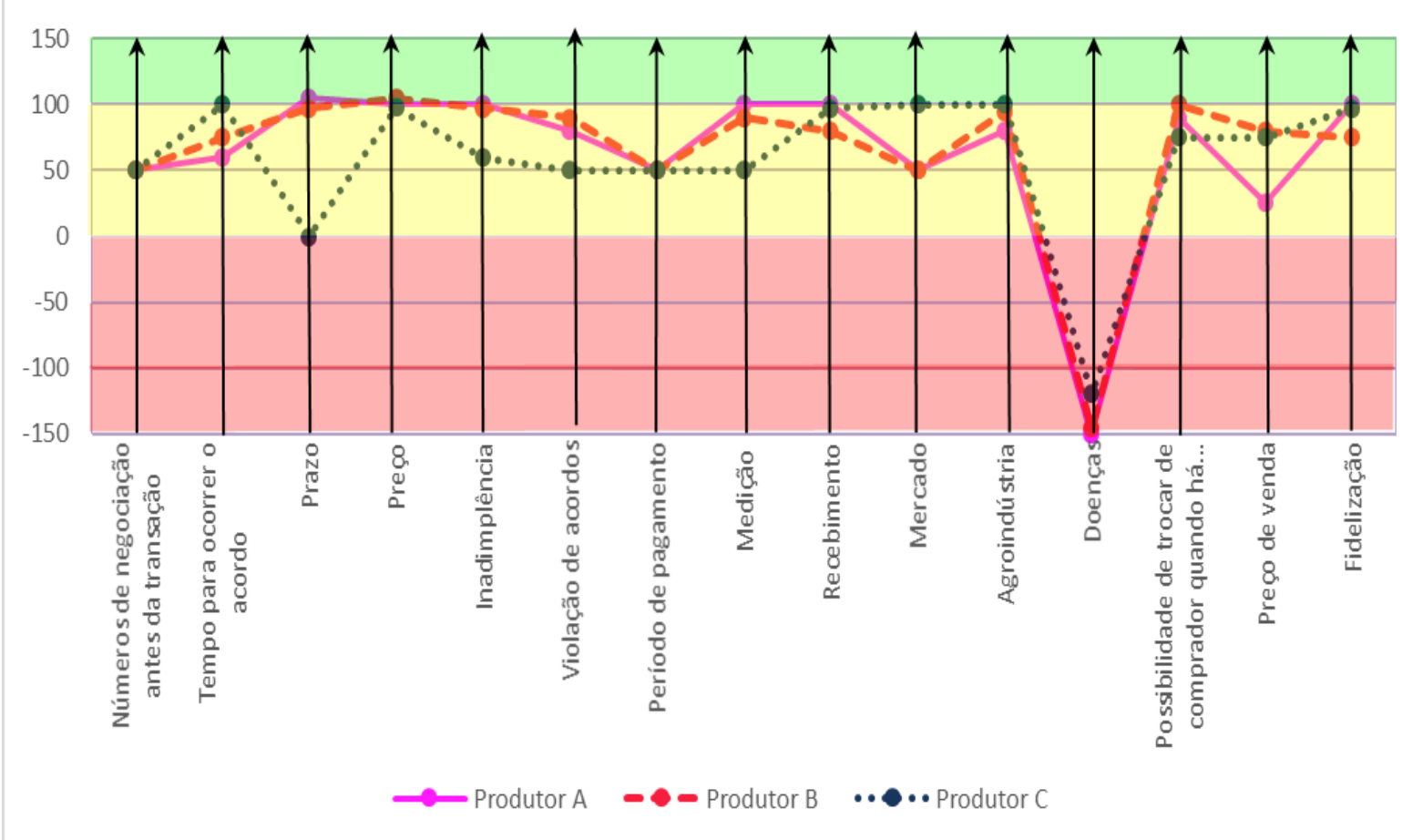

Fonte: Dados da pesquisa.

\section{CONCLUSÕES}

O presente artigo teve por objetivo compreender a percepção do produtor de laranja sobre a assimetria informacional na comercialização do produto in natura. Foi utilizada a metodologia Multicritério em Apoio à Decisão Construtivista (MCDA-C) a fim de avaliar os valores dos decisores estudados e como ocorrem as transações na comercialização de laranja. Para atingir o objetivo em questão foram realizadas entrevistas semiestruturas com três produtores de laranja residentes no noroeste do Paraná que transacionam com agroindústrias e intermediários da mesma localidade.

Para a construção do modelo a ECT foi usada como base, desta forma os pressupostos comportamentais e os atributos da transação foram escolhidos como área de interesse para estudo. Em relação aos pontos de vista fundamentais, identificou-se oportunismo, incerteza e frequência. Após isto, elaborou-se a família de pontos de vista fundamentais, que foram decompostos até serem passíveis de mensuração. Por fim criou-se os descritores para mensurar tais pontos de vista fundamentais. 


\section{BORGES; IGARASHI; SEGATE}

O modelo permitiu a análise do comportamento das transações de laranja. A partir do exposto, é possível analisar que nenhum dos pontos mapeados apresentou desempenho acima do esperado pelos decisores, e apenas o descritor doença apresentou desempenho abaixo do neutro - isto indica que as transações não são destoantes do ponto de vista dos entrevistados. Apesar da literatura indicar a existência de assimetria informacional nas transações de laranja (MELLO, 2008; MELLO, PAULILO, 2009; CARVALHO, 2015, ITO, ZYLBERSZTAJN, 2016), os decisores não possuem percepção que isto ocorre nas suas transações. Sugere-se como pesquisas futuras aumentar o número de produtores de laranja entrevistados e comparar estes resultados com entrevistas realizadas em agroindústrias dispostas na mesma região.

\section{REFERÊNCIAS}

ASSOCIAÇÃO BRASILEIRA DE CITRICULTORES. O mercado da citricultura no Brasil e as suas novas perspectivas. 2016. Disponível em: $<$ http://www.citrusbr.com/download/biblioteca/citrusbr_livro_concecitrus_2016.pdf $>$. Acesso em: 06 julho 2017.

ASSOCIAÇÃO NACIONAL DOS EXPORTADORES DE SUCOS CÍTRICOS. Cinturão Citrícola. 2017. Disponível em:

$<$ http://www.citrusbr.com/economia/?ec=07>. Acesso em: 06 julho 2017.

ASSOCIAÇÃO NACIONAL DOS EXPORTADORES DE SUCOS CÍTRICOS. Laranja e Suco. 2017. Disponível em: $<$ http://www.citrusbr.com/laranjaesuco/?ins=19>. Acesso em: 06 julho 2017.

AUGUSTO, C. A.; SOUZA, J. P.; CARIO, S. A. F. New Institutional Economics: Complementary Aspects. Ibero American Journal of Strategic Management (IJSM), v. 13, n. 1, p. 93-108, 2014.

AZEVEDO, P. F. Nova economia institucional: referencial geral e aplicação para a agricultura. Agricultura em São Paulo. v.47, n.1, p.33-52. São Paulo. 2000.

BALESTRIN, A.; ARBAGE, A. P. A perspectiva dos custos de transação na formação de redes de cooperação. RAE electron., São Paulo, v. 6, n. 1, 2007. Disponível em: $<$ http://www.scielo.br/scielo.php?script=sci_arttext\&pid=S167656482007000100008\&1 $\mathrm{ng}=\mathrm{en} \& \mathrm{nrm}=\mathrm{iso}>$. Acesso em 10 de julho de 2017.

BEGNIS, H. S. M.; ESTIVALETE, V. F. B.; PEDROSO, E. Confiança, comportamento oportunista e quebra de contratos na cadeia produtiva do fumo no sul do Brasil. Gestão \& Produção. São Carlos, v. 14, n. 2, p. 311-322, maio-ago. 2007.

CARVALHO, M. S. de. Contratos formais entre empresas processadoras de laranja. e citricultores: um estudo de múltiplos casos entre os anos-safras de 1978/79 a 2011/12 na perspectiva dos produtores. 2015. $258 \mathrm{f}$. Tese (Doutorado em Engenharia de Produção) - Programa de Pós-Graduação em Engenharia de Produção, Universidade Federal de São Carlos-UFSCar, São Carlos, 2015. 
CENTRO DE ESTUDOS AVANÇADOS EM ECONOMIA APLICADA ESALQ/USP. PIB do Agronegócio. Disponível em:

$<$ http://www.cepea.esalq.usp.br/pib/> Acesso em: 10 abril 2018.

COASE, R. H. The Nature of the Firm. Economic New Series. v. 4, p. 386-405. 1937.

COLBARI, A. A análise de conteúdo e a pesquisa empírica qualitativa. ln : SOUZA, E. M. de. (Orgs.). Metodologias e analíticas qualitativas em pesquisa organizacional: uma abordagem teórico-conceitual. Dados eletrônicos. Vitória: EDUFES, 2014, p.241 -272 .

DENZIN, N. K.; LINCOLN, Y. S. Introdução: a disciplina e a prática da pesquisa qualitativa. In: DENZIN, N. K.; LINCOLN, Y. S. (Orgs.). O planejamento da pesquisa qualitativa: teorias e abordagens. 2. ed. Porto Alegre: Artmed, 2006.

DERAL, SECRETARIA DE ESTADO DA AGRICULTURA E DO ABASTECIMENTO - SEAB DEPARTAMENTO DE ECONOMIA RURAL DERAL. DIVISÃO DE ESTATÍSTICAS BÁSICAS. 2017. Disponível em:< http://www.agricultura.pr.gov.br/sites/default/arquivos_restritos/files/documento/201909/terras_pdf_publicacao_17.pdf $>$

ENSSLIN, L.; MONTIBELleR NETO, G.; NORONHA, S. N. Apoio à Decisão: metodologia para estruturação de problemas e avaliação multicritério de alternativas. Florianópolis: INSULAR, 2001.

FARINA, E. M. M. Q. AZEVEDO, P. F.; SAES, M. S. M. Competitividade: mercado, estado e organizações. São Paulo: Singular, 1997.

FARINA, E. M. M. Q. Competitividade e coordenação de sistemas agroindustriais: um ensaio conceitual. Revista Gestão \& Produção, v. 6, n. 3, p.147-161, 1999.

IBGE, Instituto Brasileiro de Geografia e Estatística. Levantamento Sistemático da Produção Agrícola. 2010.

IGARASHI, D. C. C.; ENSSLIN, S. R.; ENSSLIN, L.; PALADINI, E. P. A qualidade do ensino sob o viés da avaliação de um programa de pós-graduação em contabilidade: proposta de estruturação de um modelo híbrido. Revista de Administração - RAUSP, v. 43, n. 2, p. 117-137, 2008.

ITO, N. C.; ZYLBERSZTAJN, D. Power and selection of contract terms: The case from the Brazilian orange juice sector. Revista de Administração da Universidade de São Paulo, v. 51, n.1, p. 5-19. São Paulo. 2016.

LAZZARINI, S. G. Estudos de caso para fins de pesquisa: aplicabilidade e limitações do método. In FARINA, Elizabeth (coord.). Estudos de caso em agribusiness. São Paulo: Pioneira. 1997.

MELLO, F. O. T. de; PAULILLO, L. F. Análise do alinhamento entre os atributos das transações e as formas de governanças empregadas na citricultura. Gestão e Produção, v. 16, n. 4. 2009.

MELLO, F. O. T. Formas Plurais de governança no complexo Agroindustrial Citrícola: análise dos produtores de laranja da microrregião de Bebedouro/SP. 2008. 189 f. Tese (Doutorado em Engenharia de Produção) - Programa de PósGraduação em Engenharia de Produção, Universidade Federal de São Carlos-UFSCar. São Carlos. 2008. 
MONDELLI, M.; ZYLBERSZTAJN, D. Determinantes dos arranjos contratuais: o caso da transação produtor-processador de carne bovina no Uruguai. Revista de Economia e Sociologia Rural. v. 46, n. 3, p. 831-868. 2008.

PONDÉ, J. L.; FAGUNDES, J.; POSSAS, M. Custo de Transação e Política de Defesa da Concorrência. Economia Contemporânea, n. 2. 1997.

RASMUSEN, E. Games and information: an introduction to game theory.

Cambrige: Blackwell Publishers, 1996.

RICHARDSON, R. J.; PERES, J. A. S.; WANDERLEY, J. C. V.; CORREIA, L. M.; PERES, M. H. M. Pesquisa Social: métodos e técnicas. 3. ed. 14reimp. São Paulo: Atlas, 2012.

ROY, B. Decision science or decision-aid science? European Journal of Operational Research, Inglaterra, v.8, n.1, p.184-203, Feb. 1993.

ROY, B. Decision-aid and decision-making. European Journal of Operational Research, 324-331. 1990.

SEAB, SECRETARIA DA AGRICULTURA E DO ABASTECIMENTO. Paraná prevê crescimento de 11,6\% na safra de laranja em 2016. 2016. Disponível em: $<$ http://www.agricultura.pr.gov.br/>. Acesso em: 06 julho 2017.

SECRETARIA DA AGRICULTURA E DO ABASTECIMENTO. Fruticultura. 2016. Disponível em:

$<$ http://www.agricultura.pr.gov.br/arquivos/File/deral/Prognosticos/fruticultura_2014_1 5.pdf>. Acesso em: 06 Julho 2017.

SILVA, A. A. da; BRITO, E. P. Z. Incerteza, racionalidade limitada e comportamento oportunista: um estudo na indústria brasileira. Rev. Adm. Mackenzie, São Paulo, v. 14, n. 1, p. 176-201., 2013.

SILVA, D. B.; CALEMAN, S. M. Q. Sistemas Agroindustriais Sustentáveis: Uma Aplicação da Economia dos Custos de Transação. Revista Brasileira de Administração Científica, v.5, n.3, p. 287- 304, 2014.

TRIVIÑOS, A. N. S. Introdução à pesquisa em ciências sociais: a pesquisa qualitativa e, educação. São Paulo: Atlas, 1987.

TURETA, C.; ALCADIPANI, R. Entre o observador e o integrante da escola de samba: os não-humanos e as transformações durante uma pesquisa de campo. Revista de Administração Contemporânea, v. 15, p. 209-227.

VIEIRA, M. M. F.; PEREIRA, B. N. Estudos etnográficos em administração. In: VIEIRA, M. M. F.; ZOUAIN, D. M. (Orgs.). Pesquisa qualitativa em administração: teoria e prática. Rio de Janeiro: FGV, 2006.

VIEIRA, A. M.; RIVERA, D. P. B. A Hermenêutica no Campo Organizacional: duas possibilidades interpretativistas de pesquisa. Revista Brasileira de Gestão de Negócios, v. 14, n. 44, p. 261-273, 2012.

WILLIAMSON, O. The economic institutions of capitalism - firms, markets, relational contracting. New York: The Free Press, 1985. 
WILLIAMSON, O. E. Comparative Economic Organization: The Analysis of Discrete Structural Alternatives. Administrative Science Quarterly, v. 36, n. 2, p. 269-296, Jun., 1991.

WILLIAMSON, O. E. Calculativeness, trust, and economic organization. The Journal of Law \& Economics, v. 36, n. 1, p. 453-486. 1993.

WILLIAMSON, O. The Mechanisms of Governance. Oxford: Oxford University Press, 1996.

WILLIAMSON, O. E. The New Institutional Economics: Taking Stock, Looking Ahead. Journal of Economic Literature, v. 38, n. 3, p. 595-613. 2000.

YIN, R. Estudo de caso: planejamento e métodos. Porto Alegre: Bookman, 2005.

ZYLBERSZTAJN, D. Estruturas de Governança e Coordenação do Agribusiness: uma aplicação da Nova Economia das Instituições. Tese de Livre-Docência, Departamento de Administração, FEA/USP, 238 p., 1995.

ZYLBERSZTAJN, Decio. Conceitos gerais, evolução e apresentação do sistema agroindustrial. In: Economia e gestão dos negócios agroalimentares: indústria de alimentos, indústria de insumos, produção agropecuária, distribuição[S.1: s.n.], 2000. 